\title{
Synthesis of carbon-supported nickel catalysts for the dry reforming of $\mathrm{CH}_{4}$
}

\author{
B. Fidalgo, L. Zubizarreta, J.M. Bermúdez, A. Arenillas, J.A. Menéndez* \\ Instituto Nacional del Carbón, CSIC, Aparatado 73, 33080 Oviedo, Spain \\ * Corresponding authors. E-mail address: angelmd@incar.csic.es \\ Tel.: +34 985 18972; Fax: +34 985297672
}

\begin{abstract}
A series of carbon-based nickel (Ni) catalysts was prepared in order to investigate the effect of the preparation method on the dispersion of $\mathrm{Ni}$ and its final catalytic activity in the dry reforming of methane, i.e. $\mathrm{CH}_{4}+\mathrm{CO}_{2}=2 \mathrm{H}_{2}+2 \mathrm{CO}$. Three parameters were studied: (i) the influence of the surface chemistry of the carbon used as support; (ii) the method of drying (conventional vs. microwave drying); and, (iii) the temperature of the reduction stage. In order to study the role of the surface chemistry of the commercial activated carbon used as support, the active carbon was tested as received and oxidized. Although a better Ni dispersion was achieved over the oxidized support, the conversions were much lower. It was also found that microwave drying offers various advantages over conventional drying, the main one being that less time is required to prepare the catalyst. Two reduction temperatures were used $\left(300\right.$ and $\left.500{ }^{\circ} \mathrm{C}\right)$, being found that it is necessary to adjust this parameter to prevent the Ni particles from sintering.
\end{abstract}




\section{Introducción}

During recent years the dry reforming of $\mathrm{CH}_{4}$ to produce synthesis gas $\left(\mathrm{H}_{2}+\mathrm{CO}\right)$ has received a lot of attention, since this method offers certain advantages over other technologies, e.g. steam reforming or partial oxidation. One of these advantages is the fact that not only $\mathrm{CH}_{4}$ but also $\mathrm{CO}_{2}$, both of which are greenhouse gases, is consumed in the reaction. Secondly, a lower $\mathrm{H}_{2} / \mathrm{CO}$ ratio is obtained, which is preferable for the synthesis of high hydrocarbon and oxygenated derivatives. Thirdly, a more efficient use in Chemical Energy Transmission Systems is achieved [1-5].

Research efforts in this field have been mainly focused on developing catalysts resistant to the deactivation resulting from carbon deposition. The way a catalyst is prepared determines its final properties. Thus, besides the metal used as catalyst, it is necessary to optimize the characteristics of the support, the interactions between the support and the metal and the parameters involved in each stage of preparation [1-5].

Nearly all of the metals in Group VIII have been studied over different supports, giving rise to good catalytic activity [1-5], nickel being the one which is leading the studies on this matter. Although $\mathrm{Ni}$ is more susceptible to coke formation, and therefore to deactivation than noble metals like $\mathrm{Rh}, \mathrm{Pt}, \mathrm{Ru}$ or $\mathrm{Ir}$, its low cost and high availability, make it very attractive for possible future implementation on an industrial scale [1-5].

The choice of support is important in the preparation of a catalyst, because it can have a great influence on the activity and deactivation of the catalyst [1-5]. A variety of materials have been tested as $\mathrm{Ni}$ support in the reaction of dry reforming of $\mathrm{CH}_{4}$, e.g. inorganic oxides $[1,2,5]$ and carbon materials [3-5]. The use of carbon materials as supports of heterogeneous catalysts has grown in the last few decades. Activated carbons are probably the most frequently used carbon materials for this application, since they offer certain advantages, such as their low cost, high mechanical resistance, high surface area, the possibility of modifying the pore size distribution, good reductive properties, easy recovery of the active metal from the spent catalyst by burning off the support and the possibility of modifying easily their surface chemistry $[3,4,6]$. This last property is a key factor, since the surface chemistry has a strong influence on the interaction between the support and the catalytic metal during the impregnation step [6]. 
If the interaction between the support and $\mathrm{Ni}$ is strong, $\mathrm{Ni}$ is more likely to be firmly deposited and well dispersed over the surface of the support [6]. This $\mathrm{Ni} /$ support interaction can be enhanced by the presence of acidic oxygen groups on the surface of the carbon support. Thus, it is sometimes necessary to subject the support to pretreatment in order to increase the presence of these groups [6].

Other preparation steps that have a significant influence on the final properties of a catalyst include drying and reduction [7-10]. The former is commonly carried out in conventional ovens, so that long periods of time are necessary for this process to be completed. A more attractive alternative technique is that of microwave drying. This method offers certain advantages over the conventional process, like the shorter drying times required (which contributes to lowering the cost of the process), and a more uniform heating (which leads to a better dispersion of the Ni over the surface of the support [7-10]). As far the reduction stage is concerned, it is necessary to determine the right reduction temperature in order to avoid sintering, as this produces catalysts with large metal particle sizes and a poor distribution.

The aim of this work was to study the influence of the drying method, the reduction temperature and the surface chemistry of the activated carbons used as supports, upon the characteristics of the carbon-supported $\mathrm{Ni}$ catalysts and upon their final catalytic activity in the dry reforming of methane.

\section{Experimental section}

\subsection{Catalysts preparation}

A series of carbon-based $\mathrm{Ni}$ catalysts was prepared from a commercial active carbon in accordance with the following steps: (i) pre-treatment of the support; (ii) impregnation of the support; (iii) drying of the catalyst; and (iv) reduction of the catalyst.

\subsubsection{Pre-treatment of the support}

A commercial activated carbon (Filtracarb FY5), whose main characteristics are summarized elsewhere [11], was used as support for producing the catalysts. This 
activated carbon was employed as received (labeled as FY5) and oxidized (labeled as FY5ox). The commercial activated carbon was oxidized by dipping it in a saturated solution of $\left(\mathrm{NH}_{4}\right) \mathrm{S}_{2} \mathrm{O}_{8}$ in $\mathrm{H}_{2} \mathrm{SO}_{4} 2 \mathrm{M}$, in a proportion of $1 \mathrm{~g}$ of activated carbon per 10 $\mathrm{mL}$ of solution. The mixture was maintained under stirring for $17 \mathrm{~h}$ and, after this period of time, the oxidized carbon was filtered and washed with hot distilled water until the filtrate became neutral and then it was dried.

\subsubsection{Impregnation of the support}

FY5 and FY5ox were impregnated using an aqueous solution of $\mathrm{Ni}\left(\mathrm{NO}_{3}\right)_{2} \cdot 6 \mathrm{H}_{2} \mathrm{O}$. The concentration of the solution was such that the final catalyst would have a Ni content of $5 \mathrm{wt} . \%$. The carbon supports were dipped into the solution in a proportion of $1 \mathrm{~g}$ of carbon to $5 \mathrm{~mL}$ of solution. The mixtures were then treated in an ultrasound bath for 7 h. After impregnation, the FY5 and FY5ox samples were labelled FY5Ni and FY5oxNi, respectively.

\subsubsection{Drying of the catalyst}

The samples were dried after the impregnating stage by using conventional or microwave heating. Thus, some impregnated samples were dried overnight in a conventional oven at $100{ }^{\circ} \mathrm{C}$ (labeled by adding E). Other samples were dried by means of microwave irradiation. The microwave devices used are described elsewhere $[12,13]$. The sample was heated up to $100{ }^{\circ} \mathrm{C}$ and maintained at this temperature for $12 \mathrm{~min}$. These samples were labeled adding MW.

\subsubsection{Reduction of the catalyst}

The catalysts were reduced in a horizontal oven, under $\mathrm{H}_{2}$ atmosphere (flow rate of 50 $\mathrm{mL}$ min-1) at two different temperatures: 300 and $500{ }^{\circ} \mathrm{C}$ (these samples were labeled by adding 300 and 500, respectively). The temperature was increased from room temperature to the pre-set operating value at a heating rate of $10{ }^{\circ} \mathrm{C} \mathrm{min}{ }^{-1}$, and held for $2 \mathrm{~h}$ before being allowed to cool down to room temperature. The final catalysts obtained and their corresponding preparation conditions are summarized in Table 1. 
Table 1. Carbon-supported Ni catalysts studied and their preparation conditions.

\begin{tabular}{|l|c|c|c|}
\hline \multicolumn{1}{|c|}{ Catalyst } & $\begin{array}{c}\text { Pre-treatment of the } \\
\text { support }\end{array}$ & Drying method & $\begin{array}{c}\text { Temperature of } \\
\text { reduction }\left({ }^{\circ} \mathrm{C}\right)\end{array}$ \\
\hline FY5Ni-E-300 & None & Electric oven & 300 \\
\hline FY5oxNi-E-300 & Oxidation & Electric oven & 300 \\
\hline FY5oxNi-E-500 & Oxidation & Electric oven & 500 \\
\hline FY5Ni-MW-300 & None & Microwave oven & 300 \\
\hline FY5oxNi-MW-300 & Oxidation & Microwave oven & 300 \\
\hline FY5oxNi-MW-500 & Oxidation & Microwave oven & 500 \\
\hline
\end{tabular}

\subsection{Catalyst characterization}

Textural characterization was carried out by $\mathrm{CO}_{2}$ adsorption-desorption isotherms at 0 ${ }^{\circ} \mathrm{C}$ and $\mathrm{N}_{2}$ adsorption-desorption isotherms at $-196{ }^{\circ} \mathrm{C}$ in a pressure range of $0-1 \mathrm{bar}$, in a Micromeritics Tristar 3000 instrument. The Dubinin-Raduskevich (DR) method [14] was applied to the $\mathrm{N}_{2}$ and $\mathrm{CO}_{2}$ adsorption isotherms, whereas the BET method was used for the $\mathrm{N}_{2}$ adsorption isotherms [15].

The Ni particle size was evaluated by X-ray diffraction and Scherrer's equation [16]. The X-ray diffractograms were collected by a Bruker D8 Advance diffractometer equipped with a Göbel mirror and a $\mathrm{Cu} K \alpha$ radiation tube $(\lambda=0.15406 \mathrm{~nm})$.

For the temperature-programmed reduction experiments (TPR), the samples were heated up to $400{ }^{\circ} \mathrm{C}$ at a heating rate of $5{ }^{\circ} \mathrm{C} \mathrm{min}-1$ in a stream containing $10 \% \mathrm{H}_{2}$ in $\mathrm{Ar}$ at a flow rate of $50 \mathrm{~cm}^{3} \mathrm{~min}^{-1}$. The sample was held at this temperature for $2 \mathrm{~h}$. Once the sample had cooled down to room temperature, the gas was changed to pure argon in order to perform the temperature programmed-desorption (TPD) experiments. In the TPD tests, the amount of $\mathrm{H}^{2}$ desorbed was evaluated by a mass spectrometer that analyzed the gases evolved when the sample was heated up to $800{ }^{\circ} \mathrm{C}$ at a rate of $15^{\circ} \mathrm{C}$ $\min ^{-1}$. 


\subsection{Dry reforming experiments}

The dry reforming experiments were carried out in a quartz reactor charged with the catalysts under study and heated in a cylindrical and vertical electric furnace up to 800 ${ }^{\circ} \mathrm{C}$. The temperature was measured by placing a thermocouple inside the catalyst bed. The composition of the gas mixture fed into the system was $50 \% \mathrm{CH}_{4}-50 \% \mathrm{CO}_{2}$ and the total volumetric hourly space velocity (VHSV) was $0.32 \mathrm{~L} \mathrm{~g}^{-1} \mathrm{~h}^{-1}$. Before the reactant gases were introduced, the system was flushed with a nitrogen flow rate of 60 $\mathrm{mL} \min ^{-1}$ for $20 \mathrm{~min}$ and then heated up to the operating temperature $\left(800{ }^{\circ} \mathrm{C}\right)$ under this inert atmosphere. The reaction was carried out for $150 \mathrm{~min}$. The outflow gas was collected in Tedlar® sample bags and analyzed in a Varian CP-3800 gas-chromatograph equipped with a TCD detector and two columns connected in series. The conversions of methane and carbon dioxide were calculated by means of Eqs. (1) and (2), respectively:

$\mathrm{CH}_{4}$ conversion, vol.\% $=100 \times\left[\left(\mathrm{H}_{2}\right)_{\text {out }} / 2\right] /\left[\left(\mathrm{CH}_{4}\right)_{\text {out }}+\left(\mathrm{H}_{2}\right)_{\text {out }} / 2\right]$

$\mathrm{CO}_{2}$ conversion, vol. $\%=100 \times\left[(\mathrm{CO})_{\text {out }} / 2\right] /\left[\left(\mathrm{CO}_{2}\right)_{\text {out }}+(\mathrm{CO})_{\text {out }} / 2\right]$

where $\left(\mathrm{CH}_{4}\right)_{\text {out }},\left(\mathrm{H}_{2}\right)_{\text {out }}$, $\left(\mathrm{CO}_{2}\right)_{\text {out }}$ and $(\mathrm{CO})_{\text {out }}$ are the methane, hydrogen, carbon dioxide and carbon monoxide concentrations in the effluent gas (vol.\%), as determined by gas chromatography.

\section{Results and discussion}

\subsection{Catalyst characterization}

Fig. 1 shows the $\mathrm{N}_{2}$ adsorption-desorption isotherms of some of the carbon-based $\mathrm{Ni}$ catalysts prepared under different conditions and their corresponding carbon supports (i.e, as received activated carbon, FY5, and the oxidized support FY50x). All the samples present type I isotherms according to the BDDT classification [17], indicating that they are microporous materials. The oxidized carbon support, FY5ox, shows an increase in $\mathrm{N}_{2}$ adsorption capacity at low relative pressures compared to the original carbon FY5, indicating that the oxidation treatment produces an increase in microporosity. This is confirmed by an increase in the $S_{\text {BET }}$ value by c.a. $95 \mathrm{~m}^{2} \mathrm{~g}^{-1}$ (see 
Table 2). In relation to the textural properties of the carbon-based Ni catalyst, no significant differences can be observed among the samples dried by different methods or reduced under different temperatures, which indicates that neither of these variables has any relevant influence on the final textural properties of the prepared catalysts. Also worthy of mention is the increase in the $\mathrm{S}_{\mathrm{BET}}$ and pore volume observed for Ni catalysts obtained when using a non-oxidized activated carbon as support. The increase in the porosity of these samples could be due to the removal of adsorbed species from the carbon surface during the reduction treatment [18]. In the case of the Ni catalysts which were prepared over oxidized activated carbon, the same effect may have taken place. However, the increase in porosity could have been partially compensated by a decrease in this parameter due to the blockage caused by the larger Ni particles present in these samples.

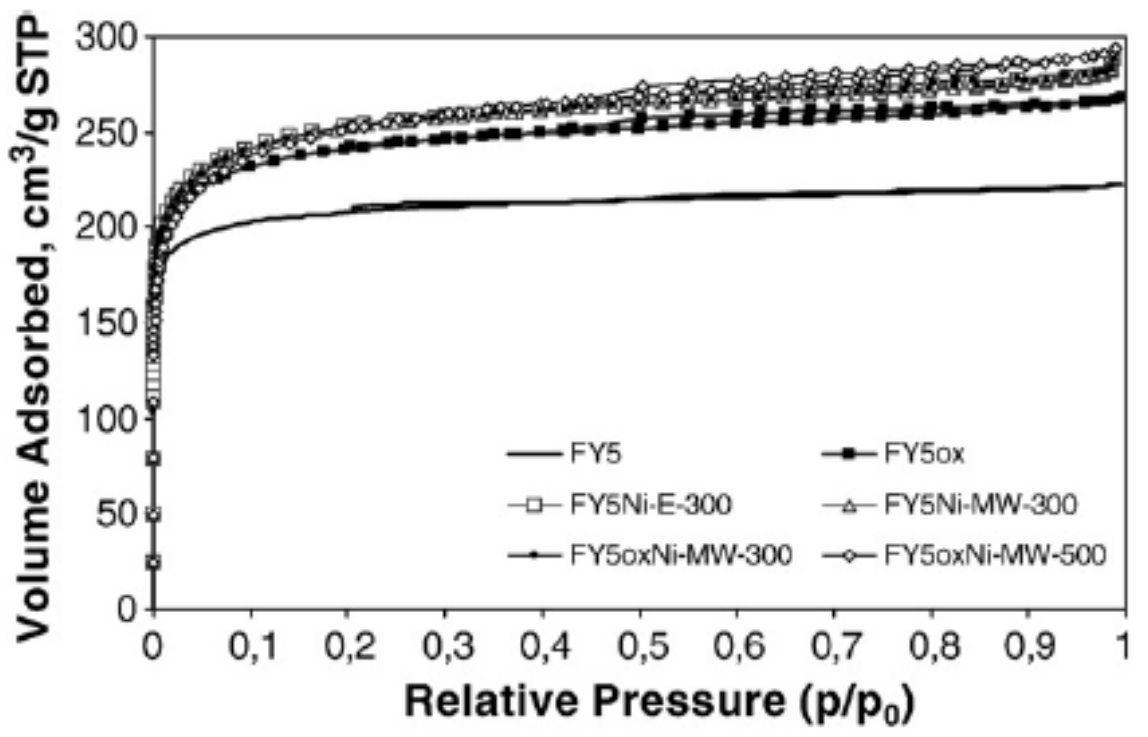

Fig. 1. $\mathrm{N}_{2}$ adsorption-desorption isotherms at $-196^{\circ} \mathrm{C}$ of carbon supports (FY5 and FY5ox) and some of the Ni-based catalysts prepared. 
Table 2. Textural parameters of carbon-supported Ni catalysts prepared under different conditions.

\begin{tabular}{|l|c|c|c|c|}
\hline \multirow{2}{*}{ Sample } & \multicolumn{3}{|c|}{$\mathrm{N}_{2}$ adsorption at $-196{ }^{\circ} \mathrm{C}$} & $\begin{array}{c}\mathrm{CO}_{2} \text { adsorption at } \\
0{ }^{\circ} \mathrm{C}\end{array}$ \\
\cline { 2 - 5 } & $\begin{array}{c}\mathrm{S}_{\mathrm{BET}} \\
\left(\mathrm{m}^{2} \cdot \mathrm{g}^{-1}\right) \pm 5\end{array}$ & $\begin{array}{c}\mathrm{V}_{\mathrm{T}} \\
\left(\mathrm{cm}^{3} \cdot \mathrm{g}^{-1}\right)\end{array}$ & $\begin{array}{c}\mathrm{W}_{0}-\mathrm{N}_{2} \\
\left(\mathrm{~cm}^{3} \cdot \mathrm{g}^{-1}\right) \pm 0.01\end{array}$ & $\begin{array}{c}\mathrm{W}_{0}-\mathrm{CO}_{2} \\
\left(\mathrm{~cm}^{3} \cdot \mathrm{g}^{-1}\right) \pm 0.01\end{array}$ \\
\hline FY5 & 825 & 0.343 & 0.323 & 0.277 \\
\hline FY50x & 930 & 0.413 & 0.352 & 0.278 \\
\hline FY5Ni-E-300 & 974 & 0.437 & 0.370 & 0.221 \\
\hline FY50xNi-E-300 & 975 & 0.446 & 0.354 & 0.239 \\
\hline FY50xNi-E-500 & 953 & 0.452 & 0.351 & 0.221 \\
\hline FY5Ni-MW-300 & 969 & 0.431 & 0.365 & 0.230 \\
\hline FY50xNi-MW-300 & 966 & 0.438 & 0.362 & 0.256 \\
\hline FY50xNi-MW-500 & 949 & 0.451 & 0.355 & 0.219 \\
\hline
\end{tabular}

Fig. 2 shows the Ni particle sizes obtained applying Scherrer's equation to the different X-ray diffractograms of the carbonsupported Ni catalyst. It can be seen that the surface chemistry of each carbon support, the drying method used to remove the solvent and reduction temperature of the catalyst have a strong influence on the size of the $\mathrm{Ni}$ particles supported on the carbon. The reduction temperature is the variable that has the greatest influence on the Ni particle size of the samples. Fig. 2 shows that a reduction temperature of $500{ }^{\circ} \mathrm{C}$ produces much larger Ni particle sizes (i.e. 130-170 $\AA$ ) than the samples reduced at $300{ }^{\circ} \mathrm{C}$. The TPR profiles of the different catalysts (not shown) show that a temperature of $300{ }^{\circ} \mathrm{C}$ is enough to reduce the $\mathrm{Ni}$ supported on the carbons studied. Higher reduction temperatures could produce the decomposition of some surface functional groups on the carbon support, promoting simultaneously the diffusion and sintering of the reduced Ni particles. It is this reason that at $500{ }^{\circ} \mathrm{C}$ large particle sizes are obtained. In contrast, the samples reduced at $300{ }^{\circ} \mathrm{C}$ present much lower particle sizes (i.e. 23-50 A). In other words, in order to achieve an acceptable Ni dispersion, the reduction temperature needs to be adjusted. 


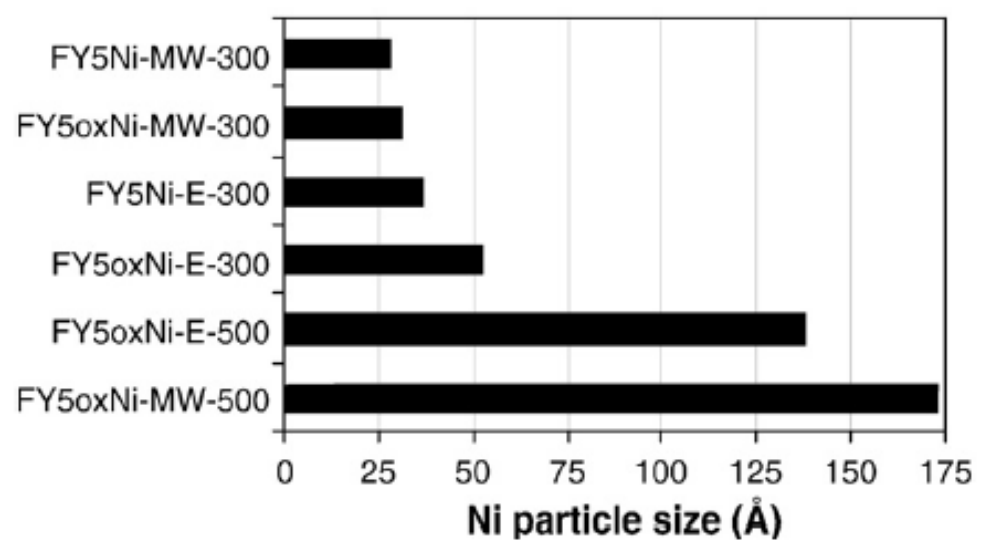

Fig. 2. Ni particle sizes in the carbon-supported Ni catalysts prepared under different conditions.

The influence of the surface chemistry of the carbon support and the drying method used on the preparation of the Ni catalyst was also studied for the samples obtained at the reduction temperature of $300{ }^{\circ} \mathrm{C}$. It was observed that, independently of the surface chemistry of the carbon support, the use of microwave drying produces Ni catalysts with smaller particle sizes, compared to the samples dried by conventional drying. This means that microwave drying favours the dispersion of $\mathrm{Ni}$ particles over the carbon support. In addition, the time required to complete the drying stage is an important parameter which must be taken into account. The use of microwave oven greatly reduces the time required for this step (from several hours to approximately $15 \mathrm{~min}$ ). As for the effect of surface chemistry, this variable was observed to have only a slight influence on the Ni particle size. In general, the Ni catalysts prepared with the oxidized support have larger Ni particle sizes. However, it should be noted that the influence of this variable seems to depend on the method used for the drying step. Thus, if microwave drying is used, the influence of the surface chemistry is not as pronounced as when conventional drying is employed. In fact, FY5Ni-MW-300 and FY5oxNi-MW300 have similar particle sizes (i.e. 28 and $30 \AA$, respectively), whereas the samples dried using conventional drying show a wider range of particle sizes (i.e. 36 and $52 \AA$, for samples FY5Ni- E-300 and FY5oxNi-E-300, respectively). Therefore, microwave heating not only diminishes the Ni particle sizes and the time of preparation, compared to conventional heating, but it also reduces the effect of the surface chemistry on the $\mathrm{Ni}$ particle size. 
Fig. 3 shows the H2 temperature-programmed desorption profiles, between 50 and 800 ${ }^{\circ} \mathrm{C}$, of the carbon-based Ni catalysts reduced at $300{ }^{\circ} \mathrm{C}$. In the case of FY5 and FY5ox, no desorption peaks can be observed (not shown). However, the Ni catalysts obtained using the non-oxidized activated carbon as support (i.e. FY5Ni-E-300 and FY5Ni-MW300) present two different peaks, the first one at low temperature, at around $80{ }^{\circ} \mathrm{C}$ for both catalysts, and the second one at around $410{ }^{\circ} \mathrm{C}$. According to previous works $[19,20]$, the first peak corresponds to hydrogen adsorbed onto the Ni which does not interact with the support. The second peak can be assigned to hydrogen that has been more thoroughly adsorbed, probably due to the presence of the spillover effect [21], as a result of aNi/support interaction. Thus, it can be assumed that the higher the temperature of this peak, the greater the interaction between the nickel and the support. The Ni catalysts prepared using oxidized activated carbon as support (i.e. FY50xNi-E-300 and FY5oxNi-MW-300) only show one peak at high temperature, i.e. the one corresponding to the hydrogen desorbed from the $\mathrm{Ni}$ with high interaction with the support. In addition, this peak appears at higher temperatures than for the Ni catalysts obtained using FY5 as support. This means that oxidation of the support favours the interaction between the Ni particles and the carbon surface. This can be explained taking into account that the incorporation of oxygen functional groups during oxidation produces a decrease in the PZC of the carbon supports, i.e., an O content of 2.8 wt.\% dry basis and $\mathrm{PZC}=10$, in the case of FY5, and 16.4 wt.\% dry basis and $\mathrm{PZC}=1.8$, in the case of FY5ox. Since the $\mathrm{pH}$ of the Ni impregnating solution is about 5, only in the cases where the PZC of the carbon support is lower than 5, the favourable electrostatic interactions between Ni cations and surface functional groups of carbon take place [22]. For this reason, when FY5ox is used as support practically all the nickel interacts with the carbon support, unlike the FY5 samples, where no attractive electrostatic interaction between the nickel and the carbon support occurs. 


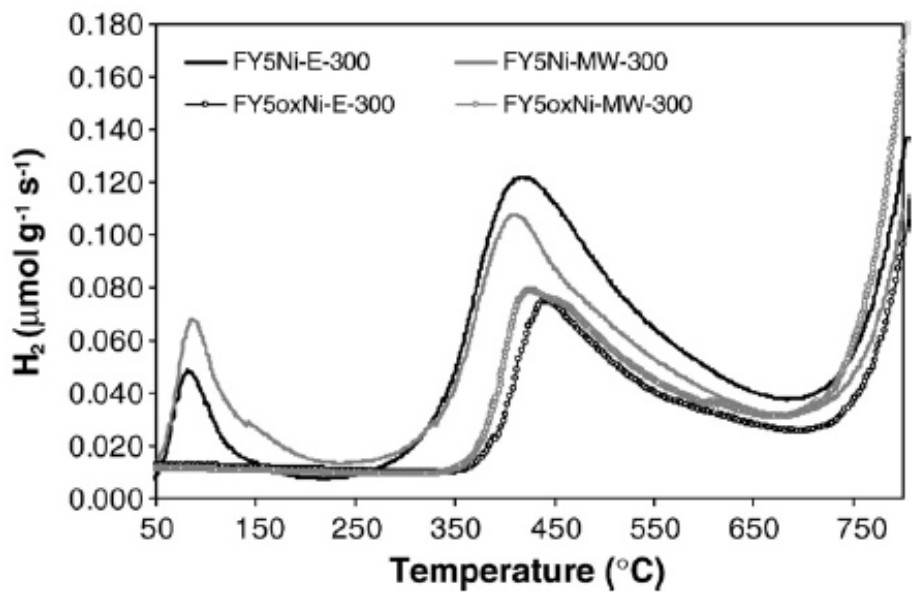

Fig. 3. Temperature-programmed hydrogen desorption profiles of carbon-supported Ni catalyst prepared under different conditions.

\subsection{Catalytic activity}

The catalytic properties of the samples studied were tested for the dry reforming reaction of $\mathrm{CH}_{4}$. Ni catalysts supported on non-oxidized carbon and reduced at $300{ }^{\circ} \mathrm{C}$ show the best performance for dry reforming (see Fig. 4). In spite of the advantages of using microwave to prepare the carbon-based $\mathrm{Ni}$ catalysts, the catalytic activity of the catalyst dried in this device is very similar to that of the catalyst prepared using conventional heating (Fig. 4.c and $d$, respectively). Interestingly, no significant difference in catalyst performance was observed when the reduction temperature was changed from 300 to $500{ }^{\circ} \mathrm{C}$ (see Fig. $4 \mathrm{e}$ and f), although the particle sizes differ greatly. This may be due to the sintering of $\mathrm{Ni}$ particles which takes place at the operating temperature of dry reforming $\left(800{ }^{\circ} \mathrm{C}\right)$, with the result that the final $\mathrm{Ni}$ particle sizes in both catalysts become similar. Therefore, although the reduction temperature needs to be adjusted to obtain an acceptable Ni dispersion, as explained above, this parameter could be considered irrelevant for the specific application of catalytic dry reforming reaction. Moreover, much lower conversions are attained when oxidized carbon is used as support instead of the as-received carbon. In fact, experiments carried out over FY5 and FY5ox (see Fig. 4a and b, respectively) demonstrated that the presence of oxygen surface groups reduced their catalytic activity dramatically. Thus, after $150 \mathrm{~min}, \mathrm{CH}_{4}$ conversion is 50\% with $\mathrm{FY} 5$ and $30 \%$ with FY5ox, whereas $\mathrm{CO}_{2}$ conversion is $50 \%$ and as low as $5 \%$, respectively. It would seem, therefore, that the negative effect of the oxidation of carbon on the conversions of $\mathrm{CH}_{4}$ 
and $\mathrm{CO}_{2}$ is stronger than the positive effect, in terms of interaction between the $\mathrm{Ni}$ particles and carbon surface, achieved by using an oxidized support. Thus, conversions over oxidized carbon-based Ni catalysts (i.e., Fig. 4e or f) are higher than conversions achieved with non-impregnated FY5ox, but similar to, or even worse, than those achieved with the original FY5.
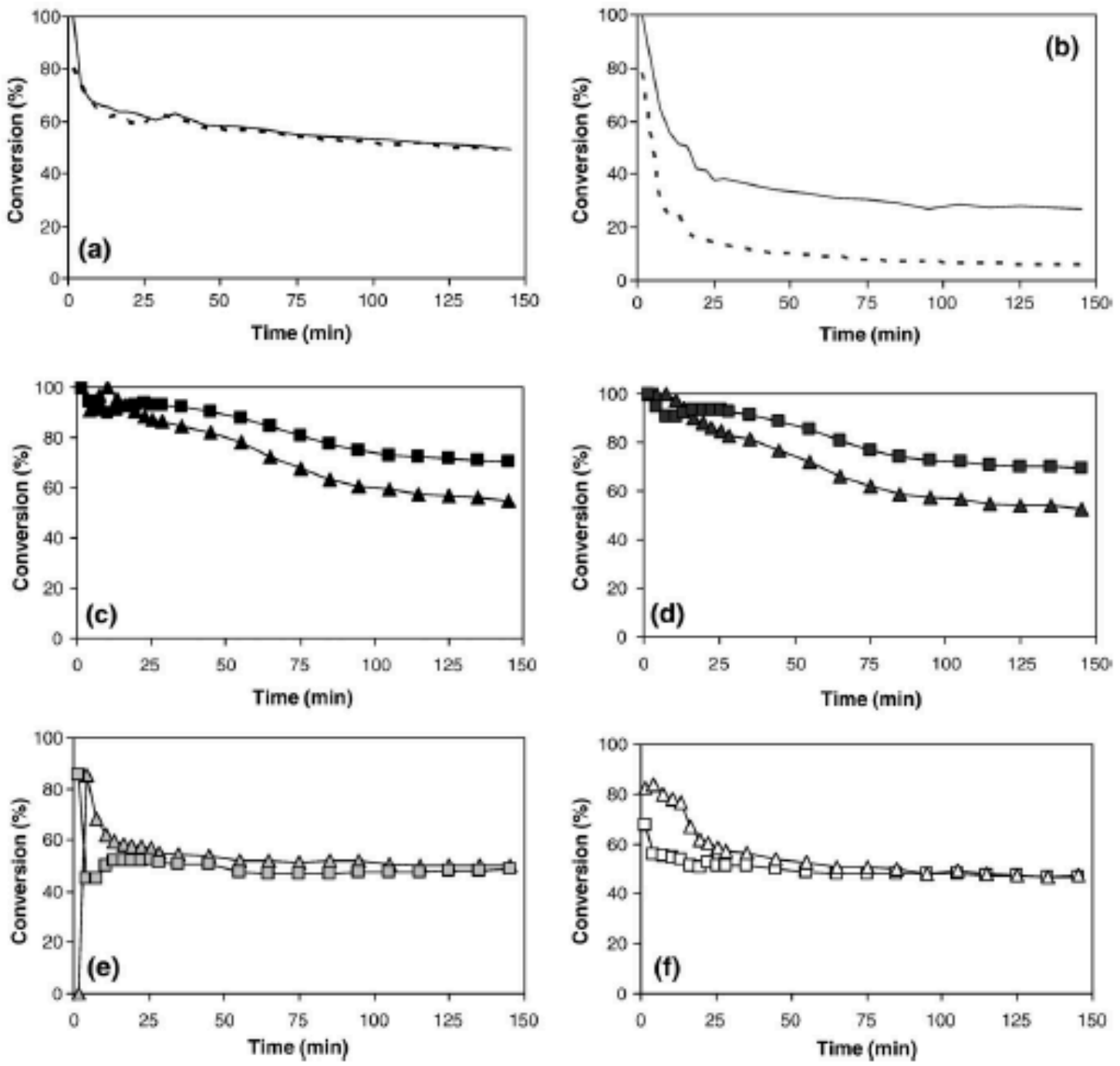

Fig. 4. $\mathrm{CH}_{4}$ conversion (continuous line or triangles) and $\mathrm{CO}_{2}$ conversion (dotted line or squares) corresponding to the dry reforming reaction carried out over carbon supports and some of the carbon-supported Ni catalyst prepared: (a) FY5; (b) FY5ox; (c) FY5NiMW-300; (d) FY5Ni-E-300; (e) FY5oxNi-MW-300; and, (f) FY5oxNi-MW-500.

\section{Conclusions}

In this work, the influence of the surface chemistry of carbons used as supports, the drying method (i.e. microwave or conventional drying) and the temperature of the 
reduction stage on the $\mathrm{Ni}$ particle size, $\mathrm{Ni}$ dispersion and final catalytic activity in the dry reforming reaction of a series of carbon-based nickel catalysts has been studied. It was found that oxidation of the carbon support favours the interaction between $\mathrm{Ni}$ particles and carbon surface, and therefore Ni dispersion. Moreover, the reduction temperature also has a great influence on the Ni particle size. The use of microwave drying rather than conventional drying offers significant advantages in the preparation of carbon-supported $\mathrm{Ni}$ catalysts: the operating time is greatly reduced, smaller $\mathrm{Ni}$ particle sizes are obtained and the influence of the surface chemistry on the Ni particle size is minimised. For the specific application of these catalysts to the dry reforming reaction, neither an improvement in $\mathrm{Ni}$ particle size nor $\mathrm{Ni}$ dispersion was found to be essential; due to the sintering of $\mathrm{Ni}$ particles that takes place at the reaction temperature $\left(800{ }^{\circ} \mathrm{C}\right)$. Other factors can have a more important role on the catalytic activity of $\mathrm{Ni}$ based catalysts in this reaction, including the oxidation of the carbon support, which reduces the catalytic properties considerably.

\section{Acknowledgements}

The authors acknowledge the financial support received from CDTI, Ministerio de Ciencia e Innovación, Spanish Government, Programa Ingenio 2010, under the project CENIT SOST-CO2 (CEN- 2008-1027). B.F., L.Z. and J.M.B. are grateful to the support received from the CSIC through the I3P and JAE programmes.

\section{References}

[1] S. Tang, L. Ji, J. Lin, H.C. Zeng, K.L. Tan, K. Li, CO2 reforming of methane to synthesis gas over sol-gel-made $\mathrm{Ni} / \gamma-\mathrm{A} 12 \mathrm{O} 3$ catalysts from organometallic precursors, J. Catal. 194 (2000) 424-430.

[2] Z. Zhang, X.E. Verykios, S.M. MacDonald, S. Affrossman, Comparative study of carbon dioxide reforming of methane to synthesis gas over $\mathrm{Ni} / \mathrm{La} 2 \mathrm{O} 3$ and conventional nickel-based catalysts, J. Phys. Chem. 100 (1996) 744-754. 
[3] J. Matos, K. Díaz, V. García, T.C. Cordero, J.L. Brito, Methane transformation in presence of carbon dioxide on activated carbon supported nickel-calcium catalysts, Catal. Lett. 109 (2006) 163-169.

[4] K. Díaz, V. García, J. Matos, Activated carbon supported Ni-Ca: influence of reaction parameters on activity and stability of catalyst on methane reformation, Fuel 86 (2007) 1337-1344.

[5] M.C.J. Bradford, M.A. Vannice, Catalytic reforming of methane with carbon dioxide over nickel catalysts I. Catalyst characterization and activity, Appl. Catal. A 142 (1996) 73-96.

[6] A. Dandekar, R.T.K. Baker, M.A. Vannice, Carbon-supported copper catalysts: I. Characterization, J. Catal. 183 (1999) 131-154.

[7] G. Bond, R.B. Moyes, D.A. Whan, Recent applications of microwave heating in catalysis, Catal. Today 17 (1993) 427-437.

[8] L. Villegas, F. Masset, N. Guilhaume, Wet impregnation of alumina-washcoated monoliths: effect of the drying procedure on $\mathrm{Ni}$ distribution and on autothermal reforming activity, Appl. Catal. A 320 (2007) 43-55.

[9] Y.K. Hwang, D.K. Kim, A.S. Mamman, S.E. Park, J.S. Chang, Fabrication of nanodispersed Pt-Sn/SBA-16 catalysts and their catalytic applications, Chem. Lett. 36 (2007) 186-187.

[10] G. Bond, R.B. Moyes, S.D. Pollington, D.A. Whan, The advantageous use of microwave radiation in the preparation of supported nickel catalysts, Stud. Surf. Sci. Catal. 75 (1993) 1805-1808.

[11] A. Domínguez, B. Fidalgo, Y. Fernández, J.J. Pis, J.A. Menéndez, Microwaveassisted catalytic decomposition of methane over activated carbon for $\mathrm{CO} 2$-free hydrogen production, Int. J. Hydrogen Energy 32 (2007) 4792-4799. 
[12] A. Domínguez, J.A. Menéndez, M. Inguanzo, J.J. Pis, Investigations into the characteristics of oils produced from microwave pyrolysis of sewage sludge, Fuel Process. Technol. 86 (2005) 1007-1020.

[13] B. Fidalgo, A. Domínguez, J.J. Pis, J.A. Menéndez, Microwave-assisted dry reforming of methane, Int. J. Hydrogen Energy 33 (2008) 4337-4344.

[14] M.M. Dubinin, The potential theory of adsorption of gases and vapors for adsorbents with energetically nonuniform surfaces, Chem. Rev. 60 (1960) 235-241.

[15] J.B. Parra, J.C. de Sousa, R.C. Bansal, J.J. Pis, J.A. Pajares, Characterization of activated carbons by BET equation. An alternative approach, Adsorp. Sci. Technol. 12 (1995) 51-66.

[16] J.R. Anderson, Structure of Metallic Catalysts, London, Academic Press, 1975.

[17] S. Brunauer, L.S. Deming, W.R. Deming, E. Teller, On a theory of the van der Waals adsorption of gases, J. Am. Chem. Soc. 62 (1940) 1723-1732.

[18] M. Zieliński, R. Wojcieszak, S. Monteverdi, M. Mercy, M.M. Bettehar, Hydrogen storage in nickel catalysts supported on activated carbon, Int. J. Hydrogen Energy 32 (2007) 1024-1032.

[19] L.M.S. Silva, J.J.M. Órfo, J.L. Figueiredo, Formation of two metal phases in the preparation of activated carbon-supported nickel catalysts, Appl. Catal. A 209 (2001) $145-154$.

[20] L. Zubizarreta, J.A. Menéndez, A. Arenillas, J.J. Pis, Improving hydrogen storage in Ni-doped carbon nanospheres, Int. J. Hydrogen Energy 34 (2009) 3070-3076.

[21] A.D. Luecking, R.T. Yang, Hydrogen spillover to enhance hydrogen storage study of the effect of carbon physicochemical properties, Appl. Catal. A 265 (2004) 259-268. 
[22] F. Rodríguez-Reinoso, The role of carbon materials in heterogeneous catalysis, Carbon 36 (1998) 159-175. 